\title{
Effect of play-based family-centered psychomotor/psychosocial stimulation on the development of severely acutely malnourished children under six in a low- income setting: a randomized controlled trial
}

Teklu Gemechu Abessa ${ }^{1,2^{*}+}$ (D, Berhanu Nigussie Worku ${ }^{2,3}$, Mekitie Wondafrash ${ }^{4}$, Tsinuel Girma ${ }^{5}$, Johan Valy ${ }^{6}$, Johan Lemmens ${ }^{6}$, Liesbeth Bruckers ${ }^{7}$, Patrick Kolsteren ${ }^{8}$ and Marita Granitzer ${ }^{2+}$

\begin{abstract}
Background: The World Health Organization (WHO) recommends incorporating psychosocial stimulation into the management of severe acute malnutrition (SAM). However, there is little evidence about the effectiveness of these interventions for SAM children, particularly when serious food shortages and lack of a balanced diet prevail. The objective of this study was to examine whether family-based psychomotor/psychosocial stimulation in a lowincome setting improves the development, linear growth, and nutritional outcomes in children with SAM.
\end{abstract}

Method: Children with SAM ( $N=339)$ admitted for treatment to the Jimma University Specialized Hospital, Ethiopia, were randomized to a control $(n=170)$ or intervention $(n=169)$ group. Both groups received routine medical care and nutritional treatment at the hospital. The intervention group additionally received play-based psychomotor/ psychosocial stimulation during their hospital stay, and at home for 6 months after being discharged from hospital. The fine motor (FM) and gross motor (GM) functions, language (LA) and personal-social (PS) skills of the children were assessed using adapted Denver II, the social-emotional (SE) behavior was assessed using adapted Ages and Stages Questionnaires: Social-Emotional, and the linear growth and nutritional status were determined through anthropometric assessments. All outcomes were assessed before the intervention, upon discharge from hospital, and 6 months after discharge (as end-line). The overtime changes of these outcomes measured in both groups were compared using Generalized Estimating Equations.

(Continued on next page)

\footnotetext{
* Correspondence: teklugem@yahoo.com

${ }^{\dagger}$ Teklu Gemechu Abessa and Marita Granitzer contributed equally to this

work.

${ }^{1}$ Department of Special Needs and Inclusive Education, College of Behavioral Sciences and Education, Jimma University, Jimma, Ethiopia

${ }^{2}$ REVAL Rehabilitation Research Center, Biomedical Research Institute, Faculty of Rehabilitation Sciences and Physiotherapy, Hasselt University, Hasselt,

Belgium

Full list of author information is available at the end of the article
}

(C) The Author(s). 2019 Open Access This article is distributed under the terms of the Creative Commons Attribution 4.0 International License (http://creativecommons.org/licenses/by/4.0/), which permits unrestricted use, distribution, and reproduction in any medium, provided you give appropriate credit to the original author(s) and the source, provide a link to the Creative Commons license, and indicate if changes were made. The Creative Commons Public Domain Dedication waiver (http://creativecommons.org/publicdomain/zero/1.0/) applies to the data made available in this article, unless otherwise stated. 
(Continued from previous page)

Results: The intervention group improved significantly on GM during hospital follow-up by 0.88 points $(p<0.001$, effect size $=0.26 \mathrm{SD}$ ), and on FM functions during the home follow-up by 1.09 points ( $p=0.001$, effect size $=0.22$

SD). Both young and older children benefited similarly from the treatment. The intervention did not contribute significantly to linear growth and nutritional outcomes.

Conclusion: Psychomotor/psychosocial stimulation of SAM children enhances improvement in gross motor functions when combined with standard nutrient-rich diets, but it can enhance the fine motor functions even when such standard dietary care is not available.

Trial registration: The trial was retrospectively registered on 30 January 2017 at the US National Institute of Health (ClinicalTrials.gov) \# NCT03036176.

\section{Background}

Malnutrition is one of the global challenges to children's health. In 2015, worldwide 156 million children under five were stunted, 50 million were wasted, and 42 million overweight [1]. In low-income countries in Africa and Asia, the prevalence of malnutrition is higher. In Ethiopia for example, it is estimated that $38 \%$ of children under five are stunted, $24 \%$ are underweight and 10\% wasted [2]. For many children, the problem already starts during intrauterine life. Poor nutrition during intrauterine life and the child's early years leads to profound and varied effects such as delayed physical growth, impaired motor and cognitive development resulting in lower IQ, more behavioral problems and deficient social skills at school age, decreased attention, deficient learning, and lower educational achievement [3-7]. Such negative consequences, however, can be ameliorated through appropriate interventions.

Providing adequate nutrition, early psychosocial stimulation at home, appropriate preschool experiences, and learning opportunities could substantially increase cognitive development of children [8] and contribute to longer-term gains in human capital [9]. Reviews of studies on nutrition and stimulation for malnourished children in general $[10,11]$ and for the severely acutely malnourished ones in particular [12] has shown that supplementing dietary rehabilitation with psychosocial stimulation can potentially reduce the adverse effects of undernutrition and improve developmental outcomes. The World Health Organization (WHO) already recommends using psychomotor/psychosocial stimulation for children in severe food shortage situations [13] and those receiving treatment for severe acute malnutrition (SAM) [13-16]. The recommendation has a dual objective: to help recover the psychomotor/psychosocial deficit, and stimulate the SAM children to regain their appetite more quickly and gain weight faster. It assumes that integrating the two treatments would have synergistic effects $[17,18]$. However, the evidence for this comes mainly from two studies; one uses a non-randomized design with mixed outcomes.

Though the WHO recommends clinical discharge with shorter hospital admission periods followed by home-based care [15], providing strict dietary rehabilitation at some home settings is also hardly possible, especially in remote and inaccessible rural areas. As most SAM children come from poor families, they return to the same poor home situation. Though ready-to-use-therapeutic food (RUTF) can be used effectively at home, children living in remote rural areas far from health centers rarely get adequate supplies of RUTF. Thus, little is known about how much psychomotor/psychosocial stimulation benefits SAM children living in settings where not even a basic diet for survival is ensured, let alone essential dietary nutrients. Moreover, since many stimulation studies have so far focused on children less than 24 months of age, much is unknown with regard to older children. Above all, the evidence supporting the recommendation of psychosocial stimulation for children with SAM is inadequate, and has been criticized for being low in quality across important outcomes [12]. Therefore, further studies are needed in different low-income settings in order to identify the best strategies to support parents in caring for their young children [19]. This study was aimed at examining the effect of playbased stimulation on the development, linear growth, and nutritional outcomes during hospital and home-based treatment of SAM children under 6 years of age in the low-income context of Jimma Zone, South West Ethiopia. The primary outcomes were developmental performances in the form of fine motor (FM) functions (such as picking things up between finger and thumb, or grasping and drawing) and gross motor (GM) functions (such as using arms, legs, feet, or entire body for crawling, running, and jumping), language (LA) and personal-social (PS) skills (such as smiling, self-feeding, helping, and playing with others) and social-emotional behaviors (SE) (such as autonomy, adaptive functioning, affect, compliance, communications, interaction with people, and self-regulation) The secondary outcomes were height/length-for-age z-score [HAZ], mid-upper-arm circumference z-score (MUACZ), weight-for-age z-score (WAZ), weight-for-height z-score (WHZ) or body-mass index-for-age z-score (BAZ) at discharge from hospital and after 6 months of follow-up at home. 


\section{Method}

\section{Study design and subjects}

A longitudinal intervention study was conducted on SAM children admitted to the nutrition rehabilitation unit (NRU) of the Jimma University Specialized Referral Teaching Hospital, South West Ethiopia. With a randomized, single blind (data collectors not knowing the treatment group of participants), parallel group trial design, eligible participants were assigned to a control or an intervention group. Data collection occurred between 8th February 2011 and 19th November 2013. The study was held up due to a delay in the adaptation process of the tools used for data collection, and it took longer than planned to enroll an adequate number of eligible participants within accessible distances for follow-up. Admission to and discharge from the NRU were based on the WHO guidelines adapted by the Ethiopian Ministry of Health for the treatment of SAM children [20]. In a small number of cases, however, patients were discharged earlier in order to free up treatment space for new, more severe patients. SAM children between 6 and 60 months of age who fulfilled the following criteria were included: weight for height or weight for length less than $70 \%$ of the median on National Centre for Health Statistics [21] of USA; or mid upper arm circumference (MUAC) < $110 \mathrm{~mm}$ with a length > $65 \mathrm{~cm}$; or, having bilateral pitting edema and having no medical complications (at Transition Phase i.e., Second phase). There are three phases (Phase I, Transition Phase and Phase II) of treatment of the SAM children, and the details are available in the protocol prepared by the Ethiopian Ministry of Health [20]. SAM children who were completely deaf or blind, who had complications hindering mobility for play, whose primary caregiver could not provide stimulation due to physical or mental disability were excluded from the study. Only one child was randomly selected from a family with more SAM children. Children from inaccessible areas and far distances (more than a $50 \mathrm{~km}$ radius of Jimma Town) were also excluded.

\section{Sample size}

The study was intended to detect a $5 \%$ difference in developmental performance ratio score between the control and the intervention groups after 6 months of follow-up. The performance ratio is the ratio of the number of test items a child performed successfully to the number of items he/she was expected to perform for his/her age. These numbers were determined in line with the test item administration and scoring guidelines presented in Denver II [22, 23]. A power of $80 \%$ was specified at a $5 \%$ significance level, assuming a $20 \%$ loss to follow-up. Estimates of the variance in developmental performance ratio scores, to be used in the power calculations, were obtained from cross-sectional data of 22 non-malnourished, healthy Ethiopian children living in the study area (36-69 months of age; mean $\pm \mathrm{SD}=$ $51.4 \pm 8.2$ ) [Snijers, Inne: Objectivity, stability and feasibility of the Denver II-Jimma: an exploratory pilot study, unpublished MA Thesis, Unpublished]. Of the four outcomes assessed using Denver II, the mean score of language $(1.05 \pm 0.14)$ was used since it was the developmental outcome with the highest variance. The data from these children were used simply because we had no other child development data collected with a culturally adapted tool to be used in the present study. Accordingly, a sample of 136 SAM children in each group was expected to sufficiently power the study. We conducted an interim analysis which showed a larger variance in developmental performance scores for SAM children than for non-malnourished healthy children. Hence, we recruited 25\% more children to each arm of the study to increase the sample size.

\section{Randomization and blinding}

Eligible children were randomized using computer-generated codes and allocated to the control $(n=170)$ and intervention $(n=169)$ groups. This was done every week by the researcher coordinating the study. Allocation concealment was ensured as the researcher had no physical access to the children.

Testers, who did not know whether a child belonged to the control or the intervention group, assessed the children in a separate room; intervention nurses worked in a separate play room which was accessible only for the intervention children and their caregivers (parents, grandparents and siblings).

\section{The intervention}

\section{Play facility and intervention nurses}

Prior to the start of the intervention, an appropriate infrastructure for psychomotor and psychosocial play activities was set up at the pediatric ward of Jimma University's Specialized Referral Teaching Hospital. A playroom and a playground were installed and furnished with basic facilities for engaging the SAM children in play-based motor, language, and personal-social activities. Three female clinical nurses, who were not members of the hospital staff, were trained as intervention nurses to stimulate the SAM children directly and also to transfer skills to caregivers on how to stimulate the SAM child through play activities. The intervention nurses who were familiar with the local cultures, and could speak the two major languages used in the area received one week of training in the theory of child development, and one month of intensive practice $(4 \mathrm{hr}$. daily) in implementing developmental stimulations. A play therapist, an occupational and a physiotherapist, special educator and a psychologist in consultation with 
a neuroscientist and nutritionists prepared the training package (see Additional file 1 to get highlight of the package).

\section{Stimulation phases and activities}

The intervention was offered in two phases: in-patient (during the Transition Phase) and out-patient (during Phase II). The first, or in-patient phase was provided in the hospital between the Transition Phase and the discharge from the hospital. Two types of sessions were offered: individual sessions in the playroom and group sessions on the playground. A minimum of 8-10 play sessions lasting for about $20-40 \mathrm{~min}$ each were planned to be held in the presence of the caregiver in the playroom only, or both in the playroom and the playground, depending on the age and health status of the child. The intervention included auditory, tactile and visual stimulation, hand-eye coordination, and different types of sensory-motor training that included fine and gross motor activities. The guiding principle was enhancing a child's holistic development-cognitive, emotional, language physical, and social-in an integrated manner by using age-appropriate play materials, cultural tools, and resources with the caregivers playing the crucial role of mediation. By attending play sessions, caregivers were trained through demonstration and active engagement on how to stimulate a child. Moreover, they received information on childcare and feeding and their importance for the development and growth of children. Simple play materials such as balls, picture cards, and animal-shaped toys were used to engage children in different age-appropriate activities that contribute to cognitive, emotional, language, physical, and social development.

The out-patient phase of the intervention occurred at home after discharge from the hospital. The standard criteria for discharge are for the SAM child to attain W/ $\mathrm{L}>=85 \%$ or $\mathrm{W} / \mathrm{H}>=85 \%$ on more than one occasion, and to have had no edema for 10 days. In addition to the play materials offered on discharge, new play material was offered during each of the three planned home visits over a 6 month follow-up. Three home visits (in the 3rd, 7th and 13th week) were made during this period to provide further stimulation to the SAM child and empower the caregivers of the SAM child. Empowerment of the caregivers included training on how to stimulate the SAM child, and further improvement of the mothers' and other family members' knowledge of childcare and feeding, proper nutrition, and stimulation. The family members were encouraged to show affection to the SAM child, be responsive to their cues, interact with them using the resources available at home and the simple play materials offered to them. The intervention utilized ideas from the Mediational Intervention for Sensitizing Caregivers program [24-26] and mediated learning experiences [27]. The key issue in the intervention was enhancing interactions between the caregivers and the target child through play, guided by a principle of Safety, Enjoyment and Stimulation. Different supervisors participated in home visits to ensure that the intervention nurses could work in a qualitative way with the target child (check whether the child had been using play materials given to him/her and had been taking part in interactive play) and the caregivers (providing information/ feedback and education on childcare, feeding and stimulation, and demonstrating how to use the new play materials offered to child). At each home visit, the play leaders first ensured that the child was using the play materials offered to him/her in line with his/her age. Educational play materials carefully selected by child therapists were given to the children, taking in account the following three age categories: 6 months to 2 years, two to 4 years, and four to 6 years. The child and caregiver (including family members and child's playmates in the neighborhood) were then introduced to techniques of play using the newly provided play materials, taking into account the level of the developmental status of the child. The mothers were encouraged to use additional local materials besides the commercial toys provided by the intervention nurses. Toys such as 'African Family' and 'African Animals', picture cards, cubes, acrobats and balls were provided for each child. Siblings and peers in the neighborhood were also encouraged to play with the target child. Some home visits were not conducted exactly on the scheduled date, and some visits were cancelled during the rainy season, thereby reducing the total number of home visits to less than the three planned moments. Some visits were made in the absence of the mother, but a caregiver was available at home. On the last home visit, the intervention nurses interviewed the caregivers using a structured questionnaire. This aimed to provide information on the progress of the child, the adherence of the parents to advice about offering home-based stimulation, and the major challenges they had encountered.

The control children received routine medical care and dietary treatment offered at the nutritional rehabilitation unit of the hospital. Although they had access to facilities in the playground, they had no access to the playroom and were not provided with stimulation and play materials. Both groups received standard formula diets (F-75, F-100, or ready-to-use therapeutic food) that contain vitamin A, folic acid, iron and all the other nutrients (potassium, magnesium and zinc) required to treat a malnourished child. F-75 and F100, or ready-touse therapeutic food (RUTF) were used for in-patient care. F-75 (75 kcal or $315 \mathrm{~kJ} / 100 \mathrm{~mL})$ is a therapeutic milk used only during the initial phase of the treatment (Phase 1), whereas F-100 (100 kcal or $420 \mathrm{~kJ} / 100 \mathrm{~mL})$ is a therapeutic milk used during the rehabilitation phase (Transition Phase and Phase 2) of the treatment. Whenever patients have a good appetite and no major medical 
complications, they enter Phase 2, when they are given RUTF (used in both in-patient and out-patient settings) or F100 and iron (used in in-patient settings only) according to look-up tables. On discharge, some packets of RUTF are given for home intake. After returning home, the SAM child is taken by a caregiver to a nearby therapeutic feeding center or health center, where registration is conducted and the child gets a Unique SAM ID number. The SAM child is followed using an individual follow-up chart and freely given RUTF periodically.

\section{Outcomes and measurements}

Outcomes were assessed by nurses trained for these purpose as testers. The testers were blinded of the treatment group to which the SAM children belong, and the intervention nurses had no role in testing..

\section{Developmental performance}

The primary outcomes of the study were the SAM children's developmental scores in FM, GM, LA, PS and SE.

Performances in FM, GM, LA and PS were assessed using the Denver II-Jimma [28], a culturally adapted and standardized screening tool to assess the development of children under 6 years of age in the Jimma zone of Ethiopia. It was created by adapting 36 of the 125 test items of the Denver II child development screening test. It has an excellent inter-rater on 123 (98\%) items and substantial to excellent test-retest reliability on 119 (91\%) items [28]. The Denver II-Jimma comprises a total of 125 test items across the four domains. It was adapted and standardized on 1597 healthy children 4 days to 70.6 months of age. The 25, 50, 75 and 90 percentile passing ages were determined for each test item as milestones. The number of test items that a child has successfully performed (passed) is described as the performance score. Most Denver II-Jimma test items assess the performance of a child through direct observation, while a few use parental reports.

The problems in SE competences (self-regulation, adaptive functioning, affect, compliance, autonomy, interaction with people and communication behaviors) were assessed using the parent-completed Ages and Stages Questionnaire: Social-Emotional (ASQ:SE), adapted to the study context (unpublished) through a collaboration between a European child psychiatrist and two local academics: a psychologist and a special educator. The adapted items were translated into two local languages commonly used in the study area, piloted and amended before use. Through a semi-structured interview with a caregiver, the social-emotional behavior of a target child was assessed on different items. The score on each item is as follows: a score of 0 indicates a normal behavior (the absence or rarely happening of a problem behavior); a score of 5 indicates the presence of a problem behavior; 10 is a problem behavior with more frequent occurrence; 15 is a problem behavior which is a concern for the caregiver. A child's total behavior score is obtained by adding up item-specific scores.

\section{Growth and nutritional status}

The secondary outcomes were linear growth, quantified by HAZ, and nutritional status, determined using MUACZ score, WAZ and WHZ for children below 60 months of age, and BAZ for children 60 or more months of age.

The child's height, weight, and MUAC were measured using a stadiometer/length-mat, calibrated digital weight scale, and MUAC tape respectively, following standard procedures [29]. At each test moment, anthropometric measurements were repeated. If different values were obtained, a third measure was taken and their average was used to calculate z-scores based on WHO standards [30].

Developmental performance, growth and nutritional status were measured at the hospital before the intervention (as baseline), on discharge, and at home 6 month after discharge from hospital (end-line).

\section{Socio-demographic information}

Socio-demographic information was collected using a structured questionnaire. Caregivers were also requested to provide information on the socio-demographics of the mother and child.

\section{Follow-up information}

During each home visit, the health and dietary condition of the intervention child, and the adherence of caregivers to run the home-based stimulation sessions were documented using a structured questionnaire. Some data on factors assumed to be affecting the performances within the intervention SAM children were gathered. Information collected include caregivers' feelings about the general health condition of the intervention SAM child, family support and engagement in the psychosocial stimulation service, the child's access to nearby health centers after discharge from hospital, the and availability of RUTF. Caregivers were asked to give their subjective rating (always, sometimes, rarely and never at all) on how often the child was getting RUTF, and whether the family provides specially prepared food for the SAM child.

\section{Assessment procedure}

After informed consent was obtained from the caregivers, developmental and anthropometric assessments were made during the Transition Phase of the nutritional treatment. Caregivers were first interviewed to complete the questionnaire on socio-demographic information. Then the child's development was assessed: first the ASQ:SE, followed by the Denver II-Jimma test. 
Lastly, anthropometric measurements were made in the following order: weight, MUAC, and length or height.

Five clinical test nurses were initially trained in anthropometric measurements and the administration of ASQ:SE and Denver II-Jimma test items. However, two who were not employed as hospital staff, and took part in data collection during adaptation and standardization of the Denver II-Jimma, collected $74 \%$ of the baseline, $81 \%$ of the discharge and $99 \%$ of the exit data. The testers did not know to which treatment group a child was allocated, though there was sometimes a possibility to guess during an exit testing whether a child had been visited during follow-up (which was the case only for the intervention children).

\section{Statistical analysis}

The developmental outcomes were summarized in terms of count scores as described earlier. These scores were entered into statistical models as continuous outcomes. Anthropometric outcomes were summarized in terms of continuous z scores. Independent two samples t-test (for the count and the continuous data) and chi-square test (for categorical data) were used to compare the baseline characteristics of the: 1) control and intervention groups and, 2) children who completed the follow-up period and children lost to follow up.

For each outcome, every child (ideally) contributed three measurements: one at baseline, one at discharge, and one at the end of follow-up. A generalized estimating equations (GEE) model with an intention-to-treat approach was used to account for the longitudinal design. The working variance-covariance matrix was an unstructured matrix, except the personal-social outcome, for which an exchangeable structure was specified due to error in convergence condition.

The primary analysis aimed to: 1) examine the change in developmental outcomes during the hospital-based follow-up (from baseline to discharge) and during the home-based follow-up (discharge to end-line), and 2) test for possible group differences in these over time changes. Therefore, the statistical model included a common intercept for the control and intervention group, and fixed effects for time, group, and their interaction. The time variable in this model is a 3-level variable (i.e. baseline, discharge and end-line). No other explanatory variables were included. Effect sizes were calculated from the GEE models by transforming the intervention effects for each outcome into standardized scores. The length of stay in the hospital (in-patient phase) and the interval within the three testing moments were not controlled for by the study design. Consequently, measurements were not taken at fixed time intervals. Therefore, the basic analysis was complemented with an analysis considering a continuous timescale. The hospital-based and the home-based follow-up periods were merged into a continuous time variable containing the number of days in the study. The time variable was used in a GEE model, where a group-specific curvilinear evolution over time was allowed.

Separate analysis was conducted for each of the primary outcomes and no multiple testing correction adjustments were made. For each outcome, the model was expanded with explanatory variables: child's sex and baseline age, baseline developmental score, and baseline WAZ or baseline MUACZ scores (for primary outcomes), and baseline anthropometric z-scores (for secondary outcomes). Variables which differed significantly between the two groups at baseline were included as covariates in models comprising the 'group' variable. To avoid multicollinearity between WAZ and MUACZ scores, the score with a greater correlation with the outcome variable was selected. The interactions between baseline age and time, and baseline score and time were also included simultaneously in the expanded model.

The final models included three variables potentially capable of modifying the treatment effect on the primary and the secondary outcomes. Each of these variables (sex, baseline age and baseline developmental level, or baseline anthropometric z-scores) and their interactions with the duration of follow-up and with treatment were separately examined. A backward selection procedure was used to obtain a parsimonious model. Statistical significance was set at $p<0.05$.

For the intervention group, a GEE model was also employed to look into the effect of aspects related to the intervention on the outcomes. The frequency of daily home-based guided stimulation of the child, the socialemotional score of the child, whether the child had been sick, receiving 'RUTF, or getting a specially prepared diet during the follow-up period were entered simultaneously in the GEE model.

Finally, the developmental performances (FM, GM, LA, PS and SE) and two anthropometric indices (WAZ and MUACZ) of the SAM children in the control and intervention groups were compared to nearly age-matched healthy children using multiple regression (with a correction for age and gender) (a) before the start of the intervention in hospital, and (b) six or more months after discharge from hospital. Data analysis was conducted using Stata (Version 12, StataCorp, College Station, Texas) [31].

\section{Ethics}

The study was carried out in accordance with the Helsinki Declaration and international ethical guidelines for biomedical research involving human subjects. Ethical approval was obtained from the Research Ethics Review Board of Jimma University (RPGC/217/2010), Ethiopia, 
and Hasselt University (CME 2010/306), Belgium. Child caregivers signed informed consent to participate in the study. SAM children in hospital were provided all routine medical care, and the facilities at the playground were accessible to all, regardless of the treatment group they were assigned to. The trial was registered at the US National Institutes of Health (ClinicalTrials.gov) \# NCT03036176.

\section{Results}

\section{Baseline characteristics of the control and the} intervention groups

In total, 339 SAM children (male $=183$; mean \pm SD age $=$ $27.4 \pm 15.1 \mathrm{mo}$, range $=6.1-65.7 \mathrm{mo}$ ) were enrolled in the study $($ control $=170$ and intervention $=169)($ Fig. 1$)$. The composition of the control and intervention group was compared for baseline child, maternal, and family characteristics. The results are presented in Table 1. The two groups differ significantly in terms of living area, maternal occupation, child's baseline WAZ and MUACZ scores. More children from urban or semi-urban areas were assigned to the intervention (30.8\% versus $15.9 \%$, $p=0.001)$. Significantly more mothers in the control group were housewives $(90.4 \%$ versus $78.2 \%, p=0.002)$. In terms of the MUACZ and WAZ scores, the intervention children had better baseline scores than the control children ( $\mathrm{z}$-score $=-3.1$ versus $-3.5, p=0.014$; and -3.6 versus $-3.9, p=0.048$ respectively). No statistically significant differences were observed between control and intervention children at baseline on child age, sex, birth order, developmental performance, family size and income. The two groups were also similar in duration of stay in hospital (mean (SD)12.12 \pm 9.7 , range 1-46 days for control group; $12.10 \pm 8.3$, range $2-48$ days for intervention group), nutritional status as measured by HAZ and WHZ or BAZ, and in maternal education. Most of the children $(80 \%)$ in each group belonged to illiterate mothers; more than $70 \%$ of them lived in a family of 3 to 6 persons; more than half were born after a second child; more than $98 \%$ lived in a family with a monthly income of less than 1500 birr (about 72 USD at the time); more than $78 \%$ of the mothers were younger than 31 years of age.

\section{Baseline characteristics related to loss to follow-up}

Of the 339 children initially enrolled, only 211 children (98 control, 113 intervention) completed the study (Fig. 1). The rate of loss to follow-up did not differ significantly between the two groups (42.4\% control versus $33.1 \%$ intervention, $p=0.08$ ). Reasons for loss (Fig. 1) include death of the children $(n=23)$, self-discharge, weekend discharge and/or failure to trace a child's address or/and failure by nurses to travel long distances for home follow-up (intervention, $n=$ 47; control, $n=55$ ), and a refusal for follow-up by one intervention child.. The baseline characteristics of children completing the study and those lost to follow-up were compared on socio-demographic profiles, and main study outcomes at baseline (child development and growth) (Table 2).

At baseline, children who completed the study and those lost to follow-up did not differ significantly except on the ASQ-SE score and location of residential area (urban / rural or small village).

On average, children completing the study had fewer social-emotional problems (as indicated by the lower scores) than children lost to follow-up (64 versus 72.1, $p=0.009$ ), and those living in small villages or rural areas were more likely to drop out ( $83 \%$ versus $73 \%, p=0.038$ ). The percentage of males and females among study completers is nearly the same $(50 \%)$. However, the percentage of lost to follow-up is higher among males: $32.7 \%$ of the girls and $42.1 \%$ of the boys were lost to follow-up.

\section{Developmental and nutritional outcomes of the study completers}

Both the control and the intervention groups that completed the study improved during the follow-up period. Table 3 summarizes the mean scores of the two groups at baseline, discharge and end-line measurements.

Age determines the scores on the four development outcomes assessed with Denver II-Jimma. However, agematching was not possible at randomization because there was a rare possibility for simultaneous enrollment of children of similar ages into hospital. Therefore, we examined whether or not there was a significant association between the group to which the children were allocated and their age distribution across six age categories (<6 mo., 12-24 mo., 24-36 mo. 36-48 mo., 48-60 mo. and $60-65 \mathrm{mo}$.). We found no statistically significant association except for age categories $>=48 \mathrm{mo}$., where more control than intervention children (20 vs $12 ., p=$ 0.001) were followed up (see Additional file 4: Table S1).

\section{Adherence to study protocol for the intervention group} Of the 113 intervention children completing the followup, five did not attend any of the planned hospital-based developmental stimulation sessions. Seventy (61.9\%) children had less than the initially planned minimum individual playroom sessions because they left the hospital; either their caregivers wanted to leave for home, or physicians decided a discharge to avail treatment space for patients with more severe cases. Six children $(5.3 \%)$ had less than three of the planned home visits.

\section{Effect of psychomotor-psychosocial stimulation on development, linear growth and nutritional status of SAM children}

The results from the primary GEE model (without adjusting for baseline covariates) to estimate the effects of the 


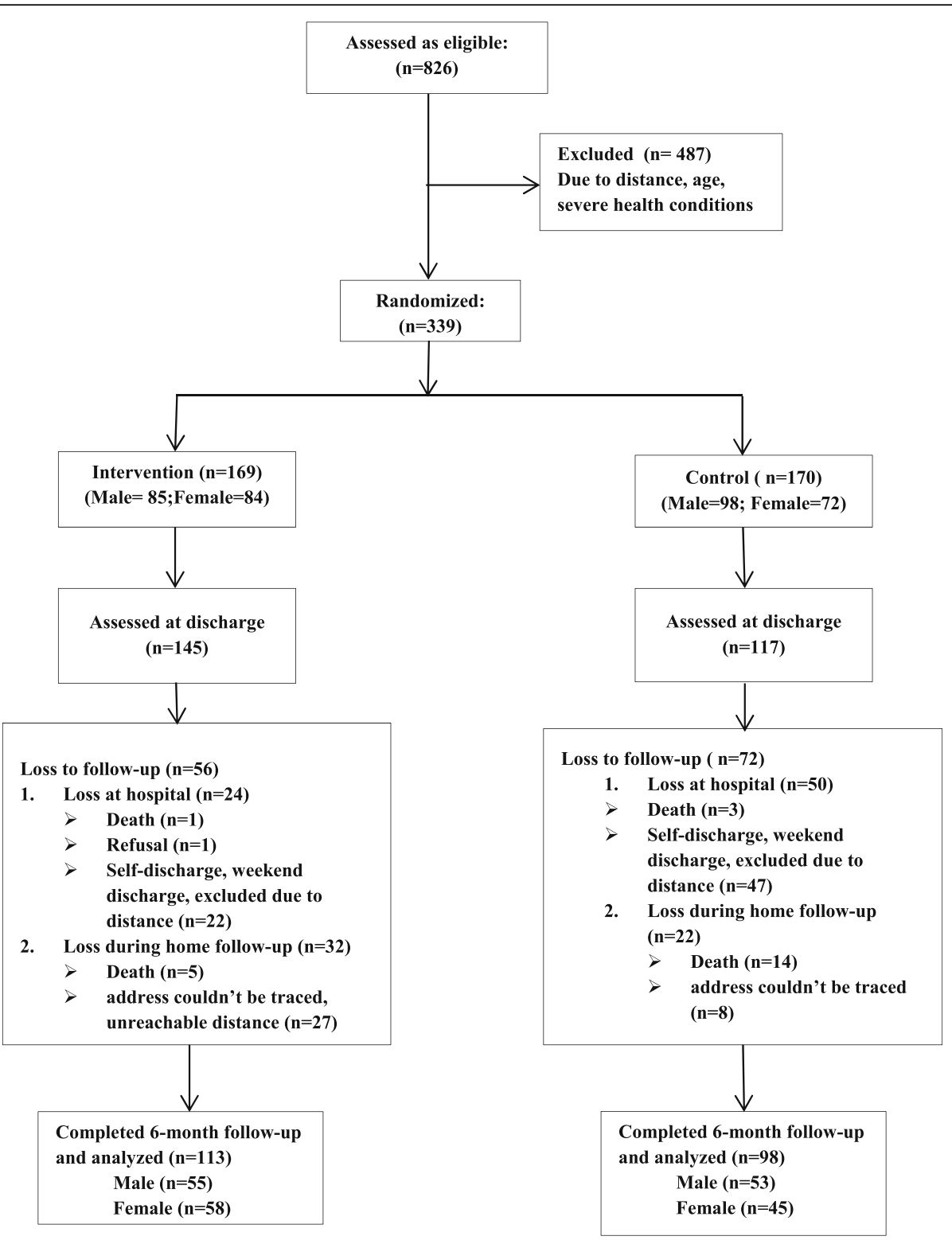

Fig. 1 Flow chart of sample enrolled and finally analyzed

intervention during (a) the hospital follow-up period, (b) the home-based follow-up period after discharge from hospital, and (c) during the whole follow-up period on primary and secondary outcomes (reflected in HAZ, MUACZ, WAZ and WHZ or BAZ scores) have been summarized (Table 4). There were some improvements over time for all outcomes (development, linear growth and nutritional status), but the improvement for the control and for the intervention groups differed significantly only in gross motor score during hospital follow-up and in fine motor score during the home follow-up period. The improvement in gross motor functions during the hospital follow-up period was higher in the intervention than the control group on average by 0.88 points $(p<0.001$, effect size $=0.26 \mathrm{SD})$. The improvement in fine motor functions was higher for the intervention than the control group during the home based follow-up period on average by 1.09 points $(p=$ 0.001 , effect size $=0.15 \mathrm{SD}$ ), and each day during the whole follow-up period by 0.13 points $(p=0.033$, effect size $=0.22 \mathrm{SD}$ ). No significant differences were observed between the two groups in linear growth (HAZ) and nutritional outcomes (MUACZ, WAZ and WHZ or BAZ) (Table 4, Additional file 5: Table S2 and Fig. 2).

\section{Moderation effects of baseline scores on treatment outcomes}

There is no significant relationship of the treatment with child's sex and baseline characteristics (age, developmental 
Table 1 Baseline characteristics (child, maternal and family characteristics) of SAM children by trial arm ( $N=339)$, displayed as n (\%) or mean $[95 \% \mathrm{Cl}]$

\begin{tabular}{|c|c|c|c|c|}
\hline Child characteristics & $N=339$ & Intervention & Control & $p$-value \\
\hline Female (n, \%) & 339 & $84(49.7)$ & $72(42.4)$ & 0.175 \\
\hline Birth order (born after second child) $(n, \%)$ & 337 & $90(53.3)$ & $97(57.7)$ & 0.589 \\
\hline Age, months & 339 & $27.5[25.3,29.7]$ & $27.3[24.9,29.7]$ & 0.908 \\
\hline HAZ baseline score & 337 & $-3.7[-4.0,-3.5]$ & $-3.8[-4.1,-3.5]$ & 0.558 \\
\hline MUACZ baseline score & 332 & $-3.1[-3.3,-2.9]$ & $-3.5[-3.8,-3.2]$ & $0.014^{*}$ \\
\hline WAZ baseline score & 338 & $-3.6[-3.8,-3.4]$ & $-3.9[-4.1,-3.6]$ & $0.048^{*}$ \\
\hline WHZ or BAZ baseline score & 337 & $-2.3[-2.5,-2.0]$ & $-2.6[-2.9,-2.3]$ & 0.128 \\
\hline Fine motor baseline score & 338 & $15.6[14.9,16.3]$ & $15.3[14.5,16.1]$ & 0.580 \\
\hline Gross motor baseline score & 339 & $16.2[15.5,17.0]$ & $16.3[15.4,17.1]$ & 0.998 \\
\hline Language baseline score & 339 & $16.6[15.7,17.6]$ & $17.1[16.0,18.2]$ & 0.546 \\
\hline Personal social baseline score & 339 & $14.2[13.3,15.0]$ & $14.0[13.0,15.0]$ & 0.773 \\
\hline Social-emotional baseline score & 336 & $67.3[62.5,72.0]$ & $66.8[62.2,71.4]$ & 0.888 \\
\hline \multicolumn{5}{|l|}{ Maternal characteristics } \\
\hline Age $(\leq 30$ years) $(n, \%)$ & 330 & $134(81.2)$ & $130(78.8)$ & 0.582 \\
\hline Education (illiterate) $(n, \%)$ & 338 & $135(79.9)$ & $135(79.9)$ & 0.100 \\
\hline Occupation (housewife) (n, \%) & 331 & $129(78.2)$ & $150(90.4)$ & $0.002^{*}$ \\
\hline \multicolumn{5}{|l|}{ Family characteristics } \\
\hline Family size (2-6 persons) ( $n, \%)$ & 339 & $121(71.6)$ & $121(71.2)$ & 0.932 \\
\hline Socio-economic status (< 2.4 USD per day) $(\mathrm{n}, \%)$ & 338 & $167(98.8)$ & $166(98.2)$ & 0.652 \\
\hline Address (rural or small village) (n, \%) & 339 & $117(69.2)$ & $143(84.1)$ & $0.001^{*}$ \\
\hline
\end{tabular}

T-test used for comparison on continuous score summarized by Mean (SD); Chi-sq summarized in Table 5.

The treatment bears no relationship to the child's sex, baseline age and baseline developmental scores, linear growth, and nutritional status measured on MUACZ and WAZ scores. However, it is related to baseline WHZ or BAZ score: for a similar length of follow-up, the intervention children with better baseline WHZ or BAZ score benefitted more from the intervention $(\beta=0.02, p=0.012)$ (Table 5).

\section{Factors affecting performance of the intervention children}

Some factors which were thought to affect the performance within the intervention SAM children were examined. After adjusting for some child conditions (health status, baseline social-emotional scores), a significant association was observed between access to RUTF and performance on gross motor and language (Table 6). Intervention children who were reported to sometimes be receiving RUTF from nearby health centers scored significantly higher in language $(\beta=1.41, p=0.032)$ than the children who rarely or never received RUTF at all. Children who were reported to have always been receiving/collecting RUTF from nearby health center scored significantly lower in GM $(\beta=-0.93, p=0.031)$. This might refer to few children who were in critical need of more RUTF because their condition did not improve. These are among only $22.6 \%$ of the children, because interviews to caregivers at the final home visit showed that $73.4 \%$ the intervened SAM children did not receive RUTF at all. Compared to those who were reported to be sick, SAM children who were not sick during the home followup scored significantly higher on personal social $(\beta=$ $0.5092, p=0.047)$ but lower on language $(\beta=-1.11, p=$ 0.024). Lower SE score (i.e., better behavior) predicts better outcomes on FM. With an increase in SE score (which marks more problem behaviors), performance on FM decreased significantly $(\beta=-0.02, p=0.016)$.

When entered alone in the model [not reported in table], the number of play sessions that the intervention SAM child received in hospital was associated significantly with all developmental outcomes, except with social-emotional scores. However, when entered simultaneously with other covariates, more play sessions were associated with higher social-emotional score $($ mean $=0.97,95 \% \mathrm{CI}[0.08$, $0.19]$ ), indicating that the children who stayed longer in hospital and attended more play sessions were those with more problem behaviors. When entered separately in the model, the duration of follow-up predicted all outcomes. Longer follow-up predicted better developmental, linear growth, and nutritional outcomes (see Additional file 6: Table S3). 
Table 2 Baseline characteristics (child, maternal and family characteristics) for the SAM children completing the study and the SAM children lost to follow-up displayed is $\mathrm{n}(\%)$ or mean $[95 \% \mathrm{Cl}]$

\begin{tabular}{|c|c|c|c|c|}
\hline & N (339) & Completers $(n=211)$ & Lost to follow-up $(n=128)$ & $p$-value \\
\hline \multicolumn{5}{|l|}{ Child characteristics } \\
\hline \multicolumn{5}{|l|}{ Demographic characteristics } \\
\hline Female $(n, \%)$ & 339 & $105(49.8)$ & $51(39.8)$ & 0.076 \\
\hline Birth order (born after second child) $(n, \%)$ & 337 & $113(53.8)$ & $74(58.3)$ & 0.258 \\
\hline Age, months & 339 & $26.7[24.7,28.7]$ & $28.5[25.7,31.3]$ & 0.303 \\
\hline \multicolumn{5}{|l|}{ Linear growth and nutritional status } \\
\hline HAZ baseline score & 337 & $-3.7[-4.0,-3.5]$ & $-3.8[-4.2,-3.5]$ & 0.641 \\
\hline MUACZ baseline score & 332 & $-3.2[-3.4,-3]$ & $-3.5[-3.8,-3.2]$ & 0.110 \\
\hline WAZ baseline score & 338 & $-3.7[-3.9,-3.5]$ & $-3.8[-4.1,-3.6]$ & 0.420 \\
\hline WHZ or BAZ baseline score & 337 & $-2.4[-2.7,-2.2]$ & $-2.5[-2.8,-2.1]$ & 0.893 \\
\hline \multicolumn{5}{|l|}{ Developmental status } \\
\hline Fine motor baseline score & 338 & $15.6[14.9,16.2]$ & $15.3[14.4,16.3]$ & 0.634 \\
\hline Gross motor baseline score & 339 & $16.3[15.6,17]$ & $16.2[15.3,17.1]$ & 0.906 \\
\hline Language baseline score & 339 & $16.4[15.5,17.3]$ & $17.6[16.3,19]$ & 0.135 \\
\hline Personal social baseline score & 339 & $14[13.1,14.8]$ & $14.3[13.2,15.4]$ & 0.644 \\
\hline Social-emotional baseline score & 336 & $64[59.8,68.1]$ & $72.1[66.7,77.5]$ & $0.009^{*}$ \\
\hline \multicolumn{5}{|l|}{ Maternal characteristics } \\
\hline Age $(\leq 30$ years) $(n, \%)$ & 330 & $166(79.4)$ & $98(81)$ & 0.732 \\
\hline Education (Illiterate) $(n, \%)$ & 338 & $203(96.6)$ & $123(96.1)$ & 0.782 \\
\hline Occupation (housewife) (n, \%) & 331 & $175(84.5)$ & $104(83.9)$ & 0.871 \\
\hline \multicolumn{5}{|l|}{ Family characteristics } \\
\hline Family size ( $2-6$ persons) ( $n, \%)$ & 339 & $158(74.9)$ & $84(65.6)$ & 0.068 \\
\hline Socio-economic status $\left(<2.4\right.$ USD per day $\left.{ }^{a}\right)(n, \%)$ & 338 & $207(98.6)$ & $126(98.4)$ & 0.921 \\
\hline Address (rural or small village) (n, \%) & 339 & $154(73)$ & $106(82.8)$ & $0.038^{*}$ \\
\hline
\end{tabular}

Finally, a comparison with age-matched healthy children showed that both the control and the intervention SAM children could not catch up after more than 6 months of follow-up, except on social-emotional behavior, in which both groups did not differ from the healthy ones (see Additional file 7: Table S4).

\section{Discussion}

The study shows play-based psychomotor/psychosocial stimulation benefits the motor (fine and gross) development of SAM children of 6 months to 6 years of age. For the gross motor functions, the intervention effect was significant during the shorter hospital-based period (12.1 \pm 8.95 , range $1-48$ days), but the effect became insignificant later during the 6 months of home follow-up. For the fine motor functions, the intervention effect became significant during the home follow-up. The effect of the intervention across the whole follow-up period was examined using analysis that combined both the hospitaland home-based follow-up periods, and showed a significant improvement in only the fine motor functions. The effect of the intervention was similar for both the younger and the older children. A non-significant but positive trend of improvement was observed in the other developmental domains (GM, LA, PS and SE) (Additional file 5: Table S2). The intervention did not improve linear growth and nutritional outcomes. There was a high loss to follow-up in the study. More loss has been observed in the control than in the intervention group. The high loss in the control group could be attributed to the lack of frequent contact and support. On the other hand, the home visits after discharge from hospital and provision of play materials might have encouraged more SAM children in the intervention group to remain in the study. Different statistical approaches other than those initially planned were applied to examine if there was a significant influence from the high loss-to-follow-up. The findings from three methods (complete case analysis, direct likelihood and multiple imputation) were compared using linear mixed model, and showed the same conclusion. 
Table 3 Group-wise comparison of the baseline ${ }^{a}$, discharge ${ }^{b}$ and end-line ${ }^{c}$ developmental and nutritional characteristics of study completers, displayed as mean [SD] and $p$-value of their difference $(N=339)$

\begin{tabular}{|c|c|c|c|c|c|c|c|c|c|c|}
\hline \multicolumn{11}{|c|}{ Developmental outcomes } \\
\hline \multirow[t]{3}{*}{ Time } & \multicolumn{2}{|l|}{ Fine motor } & \multicolumn{2}{|c|}{ Gross motor } & \multicolumn{2}{|l|}{ Language } & \multicolumn{2}{|c|}{ Personal-social } & \multicolumn{2}{|c|}{ Social-emotional } \\
\hline & \multicolumn{2}{|l|}{ Group } & \multicolumn{2}{|l|}{ Group } & \multicolumn{2}{|l|}{ Group } & \multicolumn{2}{|l|}{ Group } & \multicolumn{2}{|l|}{ Group } \\
\hline & Cont. & Int. & Cont. & Int. & Cont. & Int. & Cont. & Int. & Cont. & Int. \\
\hline Baseline $^{a}$ & $15.3[5.1]$ & $15.8[4.4]$ & $16.1[5.5]$ & $16.5[4.7]$ & $16.2[6.9]$ & $16.6[6.1]$ & $13.5[6.6]$ & $14.4[5.3]$ & $63.9[31.5]$ & $64.1[30]$ \\
\hline$p$-value ${ }^{d}$ & $p=0.200$ & & $p=0.301$ & & $p=0.360$ & & $p=0.141$ & & $p=0.483$ & \\
\hline Discharge $^{b}$ & $15.7[4.6]$ & $16.8[4.3]$ & $16.1[5.6]$ & $17.7[4.9]$ & 16.4 [6.9] & $17.3[6.6]$ & $13.8[6.1]$ & $15[5.6]$ & $48.6[27.3]$ & $50.1[29.2]$ \\
\hline$p$-value ${ }^{d}$ & $p=0.046$ & & $p=0.020$ & & $p=0.177$ & & $p=0.082$ & & $p=0.361$ & \\
\hline End-line $^{c}$ & $17.9[4.1]$ & $19.3[3.3]$ & $20.4[5.8]$ & $21.1[5.3]$ & $20.1[7.4]$ & $21.0[6.9]$ & $16.9[5.1]$ & $17.7[4.4]$ & $50.1[28.9]$ & $48.3[22.8]$ \\
\hline$p$-value ${ }^{d}$ & $p=0.003$ & & $p=0.210$ & & $p=0.186$ & & $p=0.110$ & & $p=0.695$ & \\
\hline Overall mean & $16.3[4.8]$ & $17.3[4.3]$ & $17.6[6.0]$ & $18.4[5.3]$ & $17.7[7.3]$ & $18.3[6.8]$ & $14.8[6.1]$ & $15.7[5.3]$ & $54.5[30.1]$ & $54.2[28.3]$ \\
\hline \multicolumn{11}{|c|}{ Linear growth and nutritional outcomes } \\
\hline & \multicolumn{2}{|l|}{$\mathrm{HAZ}$} & \multicolumn{2}{|l|}{ MUACZ } & \multicolumn{2}{|l|}{ WAZ } & & \multicolumn{3}{|c|}{ WHZ or BAZ } \\
\hline & Cont. & Int. & Cont. & Int. & Cont. & Int. & & Cont. & Int. & \\
\hline Baseline $^{a}$ & $-3.8[1.9]$ & $-3.7[1.8]$ & $-3.4[1.8]$ & $-3.0[1.7]$ & $-3.9[1.5]$ & $-3.5[1.4]$ & & $-2.6[1.8]$ & $-2.3[1.7]$ & \\
\hline$p$-value ${ }^{d}$ & 0.202 & & 0.042 & & 0.054 & & & 0.069 & & \\
\hline Discharge $^{\mathrm{b}}$ & $-3.9[1.9]$ & $-3.7[1.6]$ & $-3.2[1.6]$ & $-2.7[1.4]$ & $-3.8[1.4]$ & $-3.3[1.3]$ & & $-2.0[1.7]$ & $-1.8[1.4]$ & \\
\hline$p$-value ${ }^{d}$ & 0.267 & & 0.009 & & 0.123 & & & 0.222 & & \\
\hline End-line ${ }^{c}$ & $-3.7[1.6]$ & $-3.5[1.4]$ & $-1.2[1.4]$ & $-1.0[1.4]$ & $-2.5[1.5]$ & $-2.6[2.2]$ & & $-0.5[1.3]$ & $-0.6[1.4]$ & \\
\hline$p$-value ${ }^{d}$ & 0.199 & & 0.154 & & 0.596 & & & 0.644 & & \\
\hline Overall mean & $-3.8[1.8]$ & $-3.6[1.6$ & $-2.6[1.9]$ & $-2.3[1.7]$ & $-3.3[1.6]$ & $-3.2[1.7]$ & & $-1.7[1.8]$ & $-1.6[1.7]$ & \\
\hline
\end{tabular}

T-test used to determine $p$-value for mean difference

$B A Z$ body-mass-index-for-age-z score, Con control, Int intervention, HAZ height or length-for-age-z score, MUACZ mid-upper-arm-circumference-for-age z score, WAZ weight-for-age -z score, WHZ Weight-for-height/length-z score, SD standard deviation

abefore start of the psychomotor/psychosocial intervention; ${ }^{b}$ at discharge from hospital; ${ }^{c}$ after 6 months of home follow-up; ${ }^{d} p$-value for a difference between the control and the intervention means

An interesting finding is the difference in response of the gross motor and the fine motor functions to the intervention in different settings. The treatment effect on the gross motor skills was attained only during the hospital-based follow-up. For the SAM children, the diet at the nutritional rehabilitation unit of the hospital is not only better in quality, quantity and diversity, but is also provided at appropriate times with strict supervision of professionals on a daily basis. Moreover, caregivers dedicate their time fully to the child and remain in closer contact. This is not the case in a home setting, where diet is inadequate, less diversified, non-balanced and also not served in a timely manner, since caregivers have other family responsibilities. The improvement might have been enhanced by the combined and synergistic effect of the psychomotor stimulation and the dietary therapy. The stimulation may facilitate the gross motor functions to be reactivated as soon as the large muscles regain strength from dietary rehabilitation. The fact that this effect became non-significant during the home-based follow-up could be attributed to the lack of adequate essential nutrients in the diet at home. At home, the children lack the standard daily nutritional care provided at the NRU of the hospital. The inverse relationship between gross motor performance and more frequent collection of RUTF from nearby health center seems to contradict this finding. However, collection does not ensure provision of the RUTF to the child. Usually, caregivers who have serious food shortages collect and share it among other children in the family [32, 33]. Since such children do not get the required amount, the implication of frequent collection of RUTF has to be interpreted carefully. There were challenges related to the utilization of RUTF from nearby health centers. In some cases, there were shortages of RUTF, and in other cases the RUTF collected was shared among other children in the family. In some other cases, parents could not regularly collect the RUTF due to the lack of a health center in the vicinity. An interview with 112, 105 and 109 caregivers during the first, second and third (final) home visit respectively showed that $42.9,54.3$ and $73.4 \%$ of the intervened SAM children did not receive RUTF at all. If children were not able to obtain an adequate diet, they may not have 


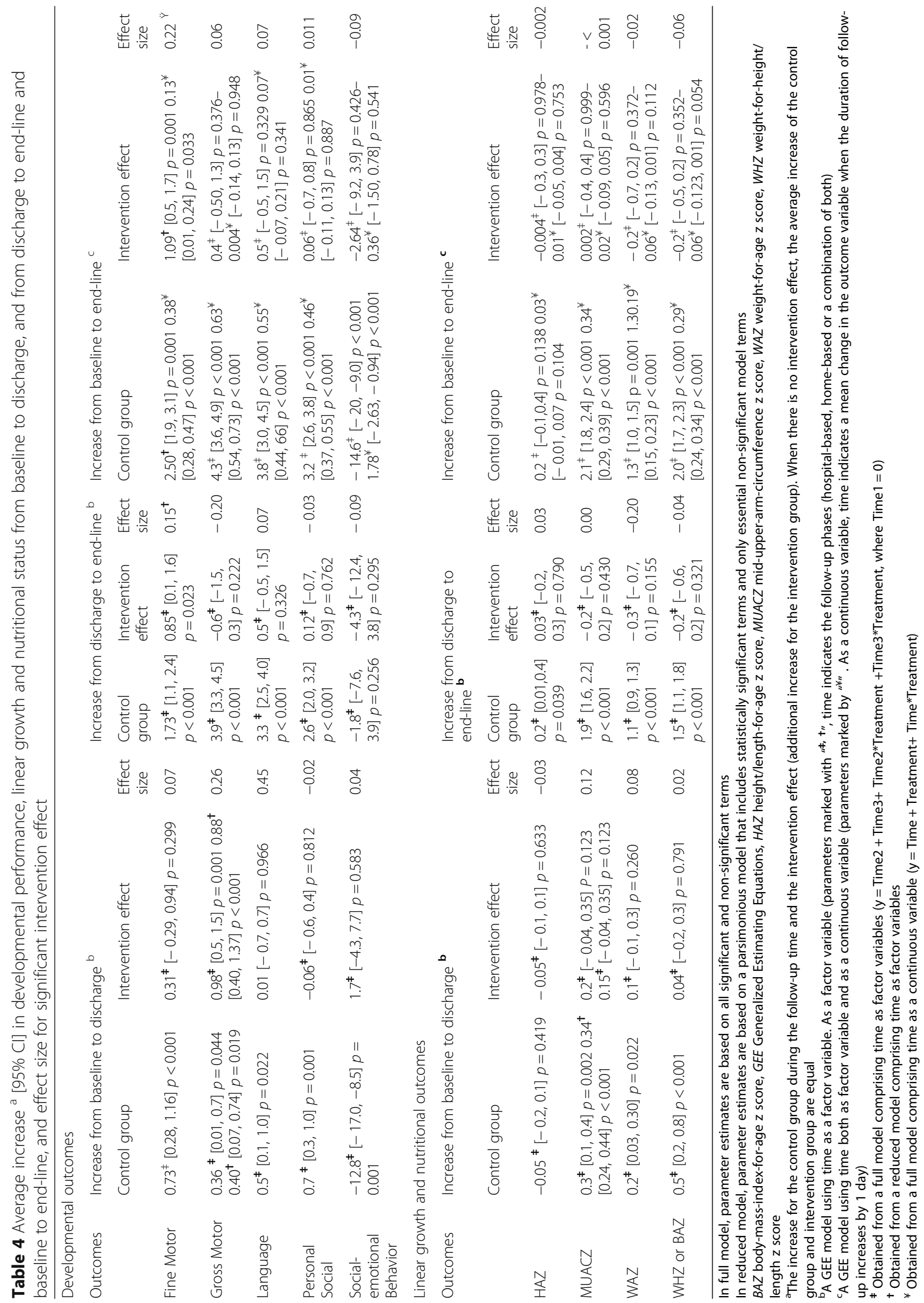




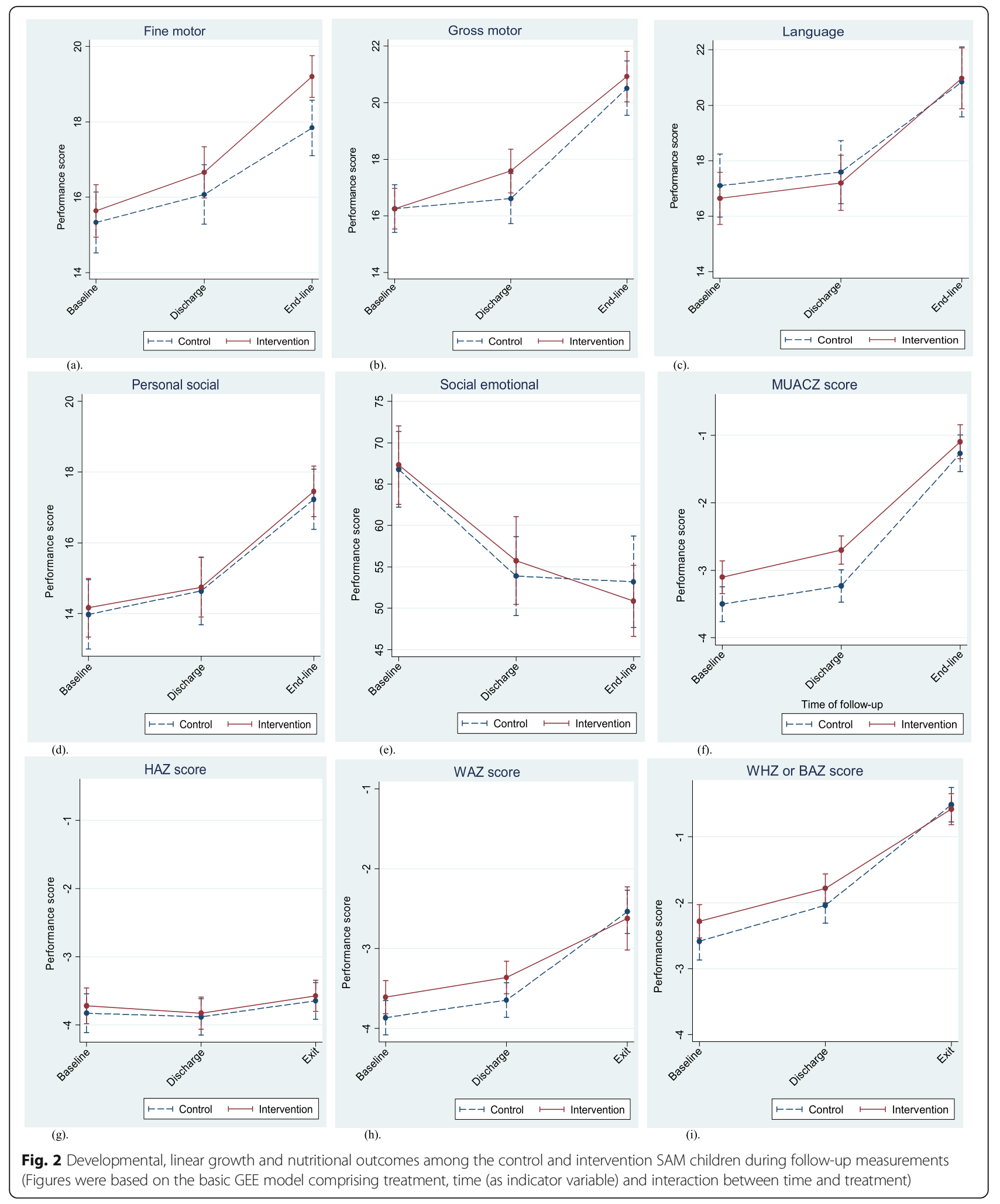

been active enough to engage in intensive motor activities. Therefore, this might have also reduced the gross motor stimulation at home, and thereby resulted in a lack of significant intervention effect.
On the other hand, the significant intervention effect observed on fine motor only at a later time (during the home follow-up) might be explained in two ways. Firstly, unlike the gross motor activities, which demand 


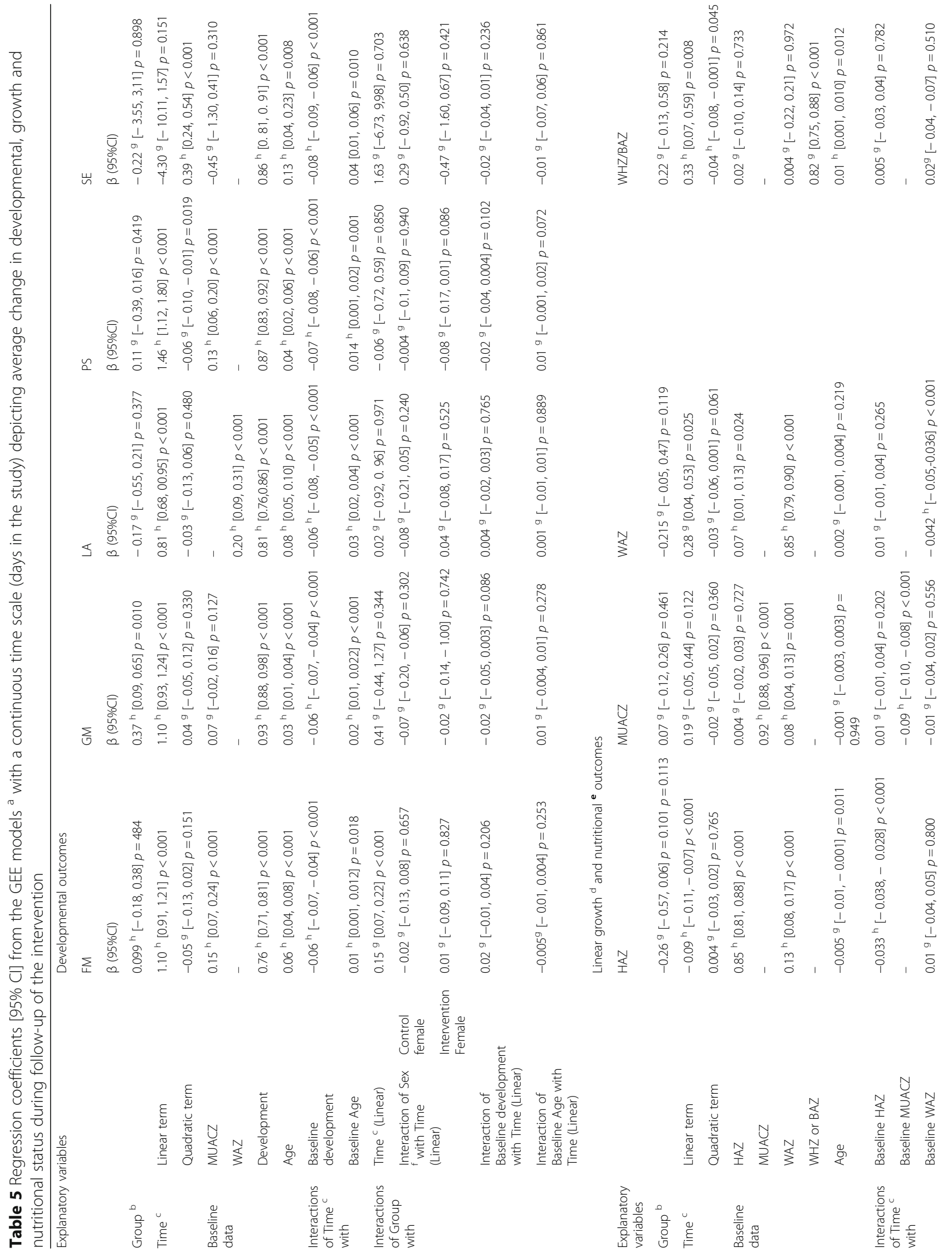




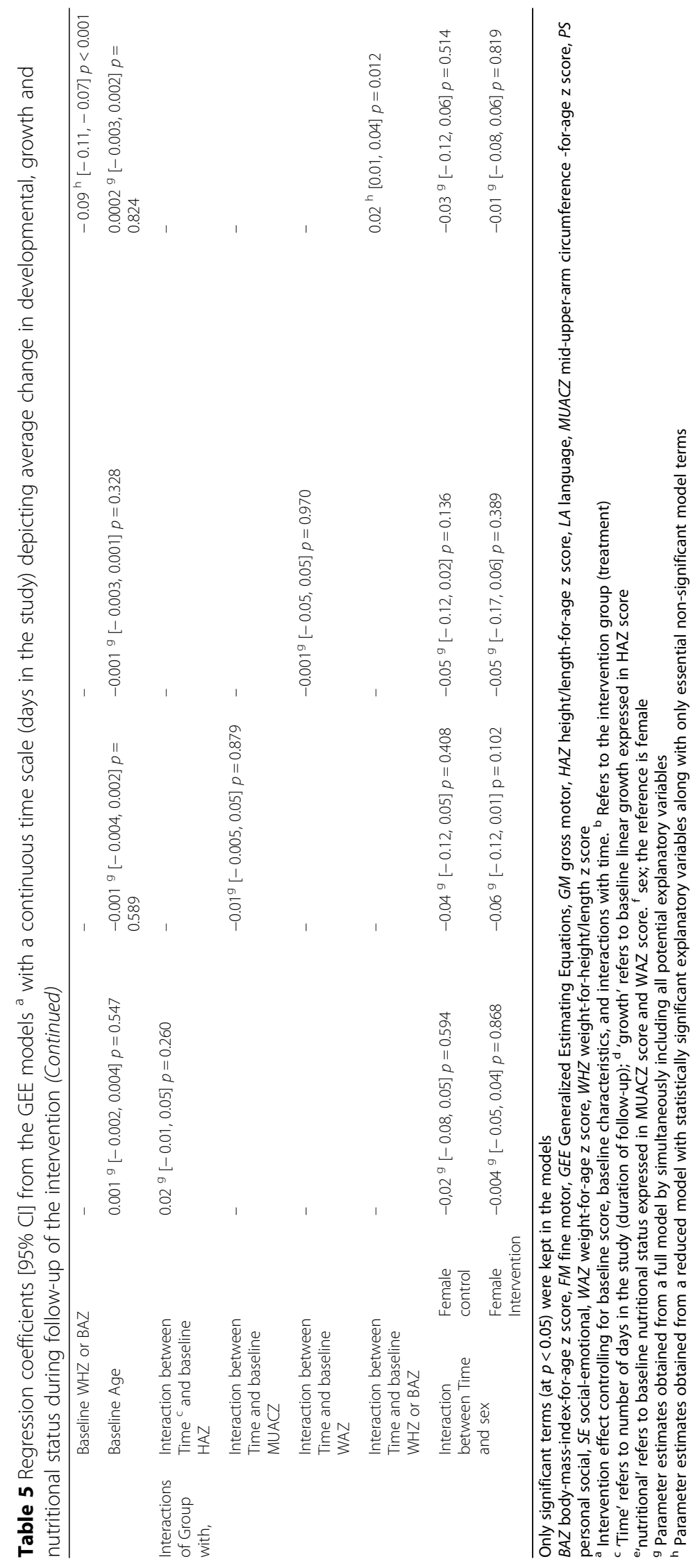




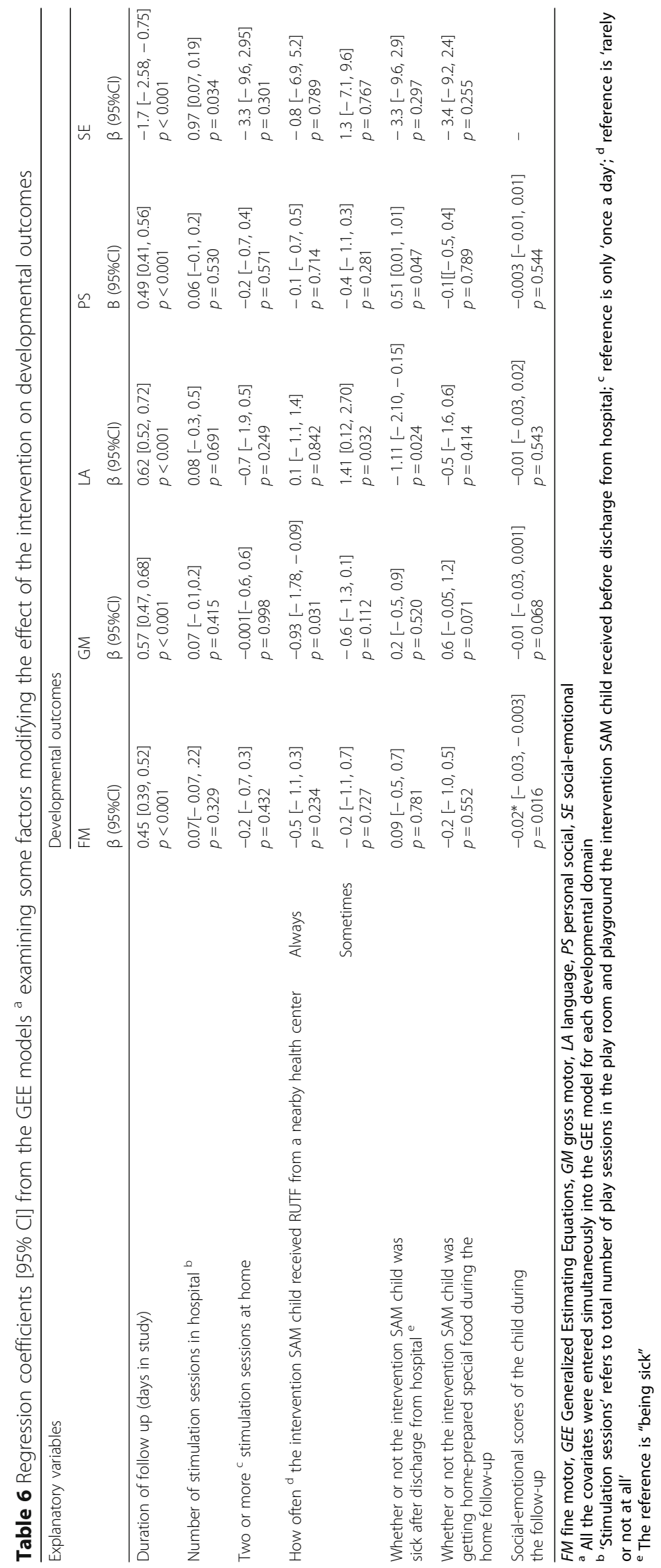


relatively more physical strength and energy, the fine motor activities might be less demanding and more feasible for SAM children to engage in and practice. Secondly, it might reflect fine motor's slower response to the intervention. Recovery in fine motor functions might require more than a mere recovery of muscles: more integration of the muscles and the brain functions through a gradual process of holistic recovery in both physical and emotional states. There have been inconsistent findings with regard to the effect of stimulation on motor outcomes. Psychosocial stimulation improved fine motor but not gross motor outcomes [12], and stimulation, with and without food supplementation had no effect on motor outcomes [18].

Though non-significant, the positive trend of improvement observed in the other areas of development could be related to such a gradual recovery process. The duration of the intervention in the present study might have been too short to generate a significant effect, as indicated in an earlier study [18]. Moreover, the intervention was not intensive. A maximum of only three home visits over a period of 6 months is not sufficient to provide adequate stimulation to the child and equip the mostly illiterate caregivers with effective stimulation techniques. Studies have shown a marked improvement in performance as the frequency of home visit increases [34, 35]. Interventions targeting high-risk children, such as those who are malnourished, might need more frequent home visits to be more beneficial [36]. None of the studies conducted so far on the stimulation of SAM children has used so few home visits as the present study. It is argued that the impact of short stimulation programs during malnutrition episodes is temporary, particularly in conditions of extreme poverty to which the children return [37]. A depriving home environment and poor nutrition remain detrimental to the outcomes of the intervention. This is the case with the present study. All families of the SAM children belong to low socio-economic groups and live in poor home environments, all of which could compromise the care and attention that the SAM child's needs.. In general, a minimum number of parenting sessions needs to be offered to sustain change when children are in an acute state and parents are challenged to provide needed stimulation.

Inconsistencies across studies on some outcomes could be related to differences in study design, duration of follow-up, the children's age and nutritional status, poverty level and maternal education, assessment tools used, and quality and intensity of home stimulation, and support from the health system.

Though their findings are inconsistent, earlier studies have targeted children under 24 months of age, or investigated the long-term effects of interventions which started at an early age and then continued later for some years [38-44]. In the present study, children 6 months to 6 years were included. It is assumed that young children are likely to have more opportunities for mother-child interactions, better stimulation, and breast-feeding, which could buffer them against extreme malnutrition. However, the present study, which addressed children of more heterogeneous ages, has shown that the treatment effect does not depend on age. It showed that both younger and older children responded similarly to the treatment, implying the potential benefits of psychosocial/psychomotor stimulation to both younger and older children under the age of six. The present study also showed that there is no significant difference in the effect of the intervention based on sex of child. But the reason for a higher loss to follow-up among boys than girls needs further investigation.

At baseline, SAM children showed marked problems in all domains of development. Gross motor was found to be the worst affected domain [45] After more than 6 months of follow-up, both the control and the intervention groups could not catch up with healthy children on nutritional and the four developmental outcomes (FM, GM, LA and PS). However, the social-emotional behavior improved markedly and was similar to that of healthy children (Additional file 6: Table S3). Studies have already shown that SAM children have behavioral abnormalities during the acute stage, which spontaneously improve during the course of recovery [37]. The improvement in the present study followed a non-linear trend. A rapid improvement during the first 4 months of follow-up seems to have slowed down afterwards (Additional file 3: Figure S1). Compared to the control SAM and the age-matched healthy children, the intervention SAM children showed substantially lower social-emotional problems (Additional file 6: Table S3).

Nonetheless, the result of our study has to be interpreted with some constraints and limitations. First, it was not possible to implement the intervention as planned. During hospital follow-up, the majority of children did not receive adequate stimulation sessions. Neither did their caregivers undergo sufficient education and training. This was because the SAM children had to leave the hospital and follow the treatment as out-patients in line with a protocol for the management of SAM children. The situation of some families also influenced the home-based stimulation. After home visits, supervisors and intervention workers often reported the presence of low motivation to engage in play among SAM children and families facing severe dietary problems. Consequently, the intervention package was less intensive and could not be implemented as planned. Second, the possibility for a contamination effect cannot be ruled out for this study. For ethical reasons, a playground meant for the study was accessible to all children. Moreover, there was a possibility for intervention and control children and their caregivers to stay in the same hospital bedroom and thus share information. Even after discharge from hospital, it was also possible that caregivers shared 
information, since randomization into control and intervention groups did not take the address of the child into account. Third, the study did not address a specific type of severe acute malnutrition, since enrollment was based on broader admission criteria. Hence, children may have edematous malnutrition, severe wasting, a combination of both, and/or a combination of stunting and wasting. Therefore, the severity of the nutritional deficiency may have varied among the study subjects. As a result, they may have responded differently to the intervention. An earlier study indicated that the presence of heterogeneous groups of conditions is a factor that constrains the interpretation of literature regarding severe acute malnutrition, and that the outcome of intervention depends to a large extent on the quality of the subsequent environment [37]. The fourth limitation is related to the sample size of the study. The statistical power computed from the cross-sectional data is insufficient to power the group*time interaction effect examined in the longitudinal data set. Ideally, a pilot study or an established literature is needed to determine a more accurate sample size. The present study lacks either of the two, and is a sort of 'hypothesis generating type'. Another limitation of the study is related to estimation of the size of the intervention effect. The GEE model estimates the intervention effect by including information of missing cases. However, the effect size calculated for the gross motor used complete case analysis due to the dependency between baseline and discharge scores. The lack of baseline and endline information on the child's diet and quality of home environment stimulation measured on the Home Observation Measurement of the Environment (the HOME) are also among the other limitations.

Regardless of its limitations, the study has some strengths. The involvement of a multidisciplinary team of local and European professionals and practitioners enabled the development of a contextually relevant intervention program integrating theory with practice. Developmental outcomes were assessed using an adapted tool, and another one adapted and standardized in the study context. The home visits and support provided at an individual family level not only allowed a single caregiver to work with the SAM child, but also with all family members, and in some case immediate neighbors and peer groups. It also provided in-depth qualitative data for a better understanding of the child's real context, and the challenges impeding the practical implementation of the intervention program. Besides including children of wider age ranges, it is the first randomized controlled trial attempted to examine the effect of adding psychomotor/ psychosocial stimulation in the treatment of SAM children both at the in-patient and the out-patient phases under the real circumstances of different family settings.

\section{Conclusions}

This study has shown that play-based stimulation contributes in the treatment of SAM children under six in low-income settings. Stimulation significantly improved the gross motor functions during the hospital stay, and the fine motor functions after discharge during the home follow-up. Both younger and older children benefited similarly from the intervention. The intervention effect on fine motor functions is, however, small. This could be due to the lack of access to an adequate and balanced diet at home, nonintensive stimulation, the short period of follow-up, and non-adherence by caregivers to strictly implement the home-based stimulation. Though the effect of the intervention is small, attaining it in such a context with limited support and resources shows that it has the potential to bring a better effect. On the other hand, the positive trends of improvement in other developmental areas show a promising effect of the intervention. It shows the possibility of designing a simple, feasible and cost-effective mechanism to engage families in a low-income context in ameliorating the damaging effect of SAM on young children. Future studies need to find the right model for improving motor, nutritional and mental status of very deprived children. Intervention packages ensuring access to balanced diets and extending longer than 6 months in duration might be better to uncover particularly the gradual developmental changes in older children.

\section{Additional files}

\section{Additional file 1: Highlight of the psychomotor/ psychosocia stimulation program. (PDF $1450 \mathrm{~kb}$ ) \\ Additional file 2: Dataset file. (CSV $466 \mathrm{~kb}$ )}

Additional file 3: Figure S1 Developmental outcomes of the control and intervention SAM children during 6 months of follow-up (DOCX 36 $\mathrm{kb})$

Additional file 4: Table S1 Baseline and end-line developmental performance and WAZ scores of SAM children ${ }^{\text {a }}$ followed up for 6 months after discharge from hospital compared with healthy children $b$ (DOCX $17 \mathrm{~kb}$ )

Additional file 5: Table S2 The overtime change ${ }^{\mathbf{a}}$ in developmental ${ }^{\mathbf{b}}$ performance, linear growth ${ }^{\mathbf{c}}$ and nutritional status ${ }^{\mathbf{d}}$ of SAM children during a follow-up in hospital as an in-patient and at home after discharge for a period of 6 months (DOCX $20 \mathrm{~kb}$ )

Additional file 6: Table S3 Regression coefficients [95\% Cl] from the GEE models ${ }^{a}$ separately examining some selected factors modifying the effect of the intervention on development, linear growth and nutritional outcomes (DOCX $18 \mathrm{~kb}$ )

Additional file 7: Table S4 Baseline and end-line developmental performance and WAZ scores of SAM children ${ }^{\text {a }}$ followed up for 6 months after discharge from hospital compared with healthy children ${ }^{b}$ (DOCX $18 \mathrm{~kb}$ )

\section{Abbreviations}

BAZ: Body-mass-index-for-age z score; FM: Fine motor adaptive; GM: Gross motor; HAZ: Height/length-for-age z score; LA: Language; mo: Month; MUAC: Mid-upper arm circumference; MUACZ: Mid-upper arm circumference Z-score; NRU: Nutrition rehabilitation unit; PS: Personal social; SAM: Severe 
acute malnutrition; SD: Standard deviation; WHO: World Health Organization; WHZ: Weight-for-height/length-for-age z score

\section{Acknowledgements}

We thank the staff at the pediatric ward of Jimma University Specialized Referral Teaching Hospital, Ethiopia, the intervention workers and nurses who walked long distances on foot to take measurements of the children followed-up, all caregivers and family members who participated in the study.

\section{Financial disclosure}

The authors have no financial relationships relevant to this article to disclose.

\section{Authors' contributions}

TGA contributed to conception and design of the study, supervised data collection, and conducted the statistical analysis, interpreted the data, and drafted the manuscript. BNW, MW, TG, JV, JL, and PK contributed to conception and design of the study, interpretation of the data and critically reviewing the manuscript. $L B$ contributed to data analysis and critically reviewing the manuscript. MG contributed to conception and design of the study, interpretation of data and drafting of the manuscript. All authors read and approved the final manuscript.

\section{Funding}

This study is part of the Jimma University-Interuniversity Collaboration partnership program funded by Vlaamse Interuniversitaire Raad - Universitaire Ontwikkelingssamenwerking (VLIR-UOS). The funder had no role in study design, data collection and analysis, decision to prepare or publish the manuscript.

\section{Availability of data and materials}

The datasets analyzed during the current study are submitted as a supplementary file (Additional file 2).

\section{Ethics approval and consent to participate}

The study was approved by the Ethical Clearance Board of Jimma University, Ethiopia (RPGC/217/2010), and the Comité voor Medische Ethiek of University of Hasselt, Belgium (CME 2010/306). Written and oral consents of parents were obtained and children were always tested in the presence of caregivers at hospital (SAM children) or at home (non-malnourished children).

\section{Consent for publication}

Not applicable.

\section{Competing interests}

The authors declare that they have no competing interests.

\section{Author details}

'Department of Special Needs and Inclusive Education, College of Behavioral Sciences and Education, Jimma University, Jimma, Ethiopia. ${ }^{2}$ REVAL Rehabilitation Research Center, Biomedical Research Institute, Faculty of Rehabilitation Sciences and Physiotherapy, Hasselt University, Hasselt, Belgium. ${ }^{3}$ Department of Psychology, College of Behavioral Sciences and Education, Jimma University, Jimma, Ethiopia. ${ }^{4}$ Department of Population and Family Health, Jimma University, Jimma, Ethiopia. ${ }^{5}$ Department of Pediatrics and Child Health, Jimma University, Jimma, Ethiopia. ${ }^{6}$ Department of Healthcare, PXL University College, Hasselt, Belgium. ${ }^{7}$-Biostat, Hasselt University, Hasselt, Belgium. ${ }^{8}$ Department of Food Safety and Food Quality, University of Gent, Ghent, Belgium.

Received: 3 May 2018 Accepted: 27 August 2019 Published online: 14 September 2019

\section{References}

1. WHO. World Health Statistics 2016: monitoring health for the SDGs, sustainable development goals. World Health Organization; 2016. https:// apps.who.int/iris/handle/10665/206498.

2. Central Statistical Agency [Ethiopia] 2016. ETHIOPIA Demographic and Health Survey 2016. Addis Ababa and Rockville: CSA and ICF; 2016.
3. Martorell R. Undernutrition during pregnancy and early childhood and its consequences for cognitive and behavioral development. In: Early child development: investing in our children's future; 1997. p. 39-83.

4. Heaver R. Strengthening country commitment to human development: lessons from nutrition. Washington DC: The World Bank; 2005.

5. Martorell R, Nguyen P. Interrelationship between growth and development in low and middle income countries. In: Nestlé Nutrition workshop series Pediatric program, vol. 65. Vevey; Philadelphia: Nestec; Lippincott Williams \& Wilkins, c1999; 2010. p. 99-121.

6. Roseboom TJ, Painter RC, AFMv A, Veenendaal MVE, SRd R. Hungry in the womb: what are the consequences? Lessons from the Dutch famine. Maturitas. 2011;70(2):141-5.

7. Prado EL, Dewey KG. Nutrition and brain development in early life. Nutr Rev. 2014;72(4):267-84

8. Santos DN, Assis AMO, Bastos ACS, Santos LM, Santos CAS, Strina A, Prado MS, Almeida-Filho NM, Rodrigues LC, Barreto ML. Determinants of cognitive function in childhood: a cohort study in a middle income context. BMC Public Health. 2008:8:202

9. Black RE, Victora CG, Walker SP, Bhutta PZA, Christian PP, Md O, Ezzati M, Grantham-McGregor S, Katz PJ, Martorell PR, et al. Maternal and child undernutrition and overweight in low-income and middle-income countries. Lancet. 2013;382(9890):427-51.

10. Grantham-McGregor SM, Fernald LCH, Kagawa RMC, Walker S. Effects of integrated child development and nutrition interventions on child development and nutritional status. Ann N Y Acad Sci. 2014;1308:11-32.

11. Aboud FE, Yousafzai AK. Global health and development in early childhood Annu Rev Psychol. 2015;66(1):433-57.

12. Daniel Al, Bandsma RH, Lytvyn L, Voskuijl WP, Potani I, Mvd H. Psychosocial stimulation interventions for children with severe acute malnutrition: a systematic review. J Glob Health. 2017;7(1):010405. https://doi.org/10.7189/ jogh.07.0104051.

13. WHO: Mental health and psychosocial well-being among children in severe food shortage situations. In., vol. WHO/MSD/MER/06.1: Department of Mental Health and Substance Abuse (MSD) mental health: Evidence and Research (MER); 2006.

14. WHO. Management of severe malnutrition: a manual for physicians and other senior health workers. Geneva: World Health Organization; 1999.

15. Guideline: updates on the management of severe acute malnutrition in infants and children [www.who.int/about/licensing/copyright_form/en/index.html]. Accessed 21 June 2017.

16. Ashworth A, Khanum S, Jackson A, Schofield C. Guidelines for the inpatient treatment of severely malnourished children. Geneva: World Health Organization; 2003.

17. Nahar B, Hamadani JD, Ahmed T, Tofali F, Raman A, Huda S, GranthamMcGregor S. Effects of psychosocial stimulation on growth and development of severely malnourished children in a nutrition unit in Bangladesh. Eur J Clin Nutr. 2009;63(6):725-31.

18. Nahar B, Hossain MI, Hamadani JD, Ahmed T, Grantham-McGregor S, Persson L-A. Effects of a community-based approach of food and psychosocial stimulation on growth and development of severely malnourished children in Bangladesh: a randomised trial. Eur J Clin Nutr. 2012;66:701-9 edn: Macmillan Publishers Limited.

19. Nahar B, Hossain Ml, Hamadani JD, Ahmed T, Grantham-McGregor S, Persson L-A. Effects of psychosocial stimulation on improving home environment and child-rearing practices: results from a community-based trial among severely malnourished children in Bangladesh. BMC Public Health. 2012;12:622. https://doi.org/10.1186/1471-2458-12-622.

20. Chamois S, Golden M, Grellety Y. Ethiopia protocol for the management of severe acute malnutrition. Addis Ababa: Ethiopian Federal Ministry of Health; 2007.

21. Hamill PW, Drizd TA, Johnson CL, Reed RB, Roche AF. NCHS growth curves for children birth-18 years. USA: National Center for Health Statistics; 1977.

22. Frankenburg WK, Dodds JB, Archer P, Shapiro H, Bresnick B. Denver II training manual. Denver: Denver Developmental Materials, Inc; 1992.

23. Frankenburg Wk,Dodds JB, Archer P, Shapiro H, Bresnick B. Denver ॥ Technical Manual. Denver, Co, USA.: Denver Developmental Materials, Inc; 1992

24. Klein PS. Promoting flexibility in young children's mind within the family - a cross cultural view. Belgium: Int J Early Childhood. 1987;19(2):51-60.

25. Klein PS. Improving the quality of parental interaction with very low birth weight children: a longitudinal study using a mediated learning experience mode. Infant Ment Health J. 1991;12(4):321-37. 
26. Klein PS. Early intervention: cross-cultural experiences with a mediational approach. New York: Routledge; 1996

27. Feuerstein R, Klein PS, Tannenbaum AJ. Mediated learning experience (MLE) : theoretical, psychosocial and learning implications. Tel Aviv: Freund Publishing House LTD; 1999.

28. Abessa TG, Worku BN, Kibebew MW, Valy J, Lemmens J, Thijs H, Yimer WK Kolsteren P, Granitzer M. Adaptation and standardization of a Western tool for assessing child development in non-Western low-income context. BMC Public Health. 2016;16:652.

29. WHO Expert Committee. Physical status : the use of and interpretation of anthropometry, report of a WHO expert committee. Geneva: World Health Organization; 1995

30. WHO. WHO Anthro software (version 3.2.2, January 2011) and macros. Geneva: WHO Anthro; 2011.

31. StataCorp. Stata Statistical Software: Release 12. College Station: StataCorp LP: 2011

32. Eklund M, Girma T. Effectiveness of integrated outpatient care of severe acute malnutrition in Ethiopia. In: Field exchange: ENN; 2008. p. 7.

33. Yebyo HG, Kendall C, Nigusse D, Lemma W. Outpatient therapeutic feeding program outcomes and determinants in treatment of severe acute malnutrition in Tigray, northern Ethiopia: a retrospective cohort study. PLoS One. 2013;8(6):e65840.

34. Powell C, Grantham-McGregor S. Home visiting of varying frequency and child development. Pediatrics. 1989;84(1):157-64

35. Wallander JL, Biasini FJ, Thorsten V, Dhaded SM, DMd J, Chomba E, Pasha O, Goudar S, Wallace D, Chakraborty H, et al. Dose of early intervention treatment during children's first 36 months of life is associated with developmental outcomes: an observational cohort study in three low/lowmiddle income countries. BMC Pediatr. 2014;14:281.

36. Gardner J, Walker S, Powell C, Grantham-McGregor S. A randomized controlled trial of home-visiting intervention on cognition and behavior in term low birth weight infants. J Pediatr. 2003;143:634-9.

37. Grantham-McGregor S. A review of studies of the effect of severe malnutrition on mental development. J Nutr. 1995:125(Supplement):2233S-8S.

38. Walker SP, Chang SM, Powell CA, Simonoff E, Grantham-McGregor SM Effects of psychosocial stimulation and dietary supplementation in early childhood on psychosocial functioning in late adolescence: follow-up of randomised controlled trial. Br J Med. 2006:333(7566):472.

39. Walker SP, Chang SM, Powell CA, Grantham-McGregor SM. Effects of early childhood psychosocial stimulation and nutritional supplementation on cognition and education in growth-stunted Jamaican children: prospective cohort study. Lancet. 2005;366(9499):1804-7.

40. Chang SM, Walker SP, Grantham-McGregor S, Powell CA. Early childhood stunting and later behaviour and school achievement. J Child Psychol Psychiatry. 2002;4(36):775-83.

41. Grantham-McGregor SM, Walker SP, Chang SM, Powell CA. Effects of early childhood supplementation with and without stimulation on later development in stunted Jamaican children. Am J Clin Nutr. 1997;66(2):247-53.

42. Grantham-McGregor S, Schofield W, Powell C. Development of severely malnourished children who received psychosocial stimulation: six-year follow-up. J Pediatr. 1987:79(2):247-54

43. Grantham-McGregor S, Powell C, Walker S, Chang S, Fletcher P. The longterm follow-up of severely malnourished children who participated in an intervention program. Child Dev. 1994;65(2 Spec no:428-39.

44. Grantham-McGregor S, Schofield W, Harris L. Effect of psychosocial stimulation on mental development of severely malnourished children: an interim report. Pediatrics. 1983;72(2):239-43.

45. Abessa TG, Bruckers L, Kosteren P, Granitzer M. Developmental performance of hospitalized severely acutely malnourished under-six children in lowincome setting. BMC Pediatr. 2017;17:197.

\section{Publisher's Note}

Springer Nature remains neutral with regard to jurisdictional claims in published maps and institutional affiliations.

Ready to submit your research? Choose BMC and benefit from:

- fast, convenient online submission

- thorough peer review by experienced researchers in your field

- rapid publication on acceptance

- support for research data, including large and complex data types

- gold Open Access which fosters wider collaboration and increased citations

- maximum visibility for your research: over $100 \mathrm{M}$ website views per year

At $\mathrm{BMC}$, research is always in progress.

Learn more biomedcentral.com/submissions 